\title{
DETERMINATION OF THE CHEMICAL COMPOSITION OF GRAPE SEED POWDERS BY GC-MS ANALYSIS
}

\author{
Olena Gorodyska \\ Department of Bakery, Confectionary, Pasta and Food Concentrates Technology \\ Kharkiv State University of Food Technology and Trade \\ 333 Klochkivska str., Kharkiv, Ukraine, 61051 \\ gorelena84@gmail.com \\ Nataliya Grevtseva \\ Department of Bakery, Confectionary, Pasta and Food Concentrates Technology \\ Kharkiv State University of Food Technology and Trade \\ 333 Klochkivska str., Kharkiv, Ukraine, 61051 \\ grevtseva66@gmail.com \\ Olga Samokhvalova \\ Department of Bakery, Confectionary, Pasta and Food Concentrates Technology \\ Kharkiv State University of Food Technology and Trade \\ 333 Klochkivska str., Kharkiv, Ukraine, 61051 \\ sam55ov@gmail.com \\ Sergey Gubsky \\ Department of Chemistry, Microbiology and Hygiene of Food \\ Kharkiv State University Food Technology and Trade \\ 333 Klochkivska str., Kharkiv, Ukraine, 61051 \\ s.gubsky@hduht.edu.ua
}

\begin{abstract}
Substantiation of the expedience of using of natural antioxidants for inhibiting of oxidative and hydrolytic rancidity in confectionary products is an urgent direction. The offered way of solving the problem is to use a defatted grape seed powder, a product, obtained as wastes of vine-making as a source of antioxidants. For this aim, there were realized experimental studies of water-alcohol extracts (ethanol, isopropanol) by the method of gas chromatography with mass-spectroscopic detection (CG-MS) of the chemical composition of grape seed powders under industrial conditions. The obtained data allowed to establish that the studied extracts contain an essential amount of phenol compounds of the different origin: aromatic acids - gallic and egallic acids; resveratrol; flavonoids - quercetin and its derivatives, catechine, epicatechine, campferol and others alongside with esters of fatty acids. These components are strong antioxidants, and their introduction to a grape seed powder must favor inhibition of the oxidizing process of fats in fat-containing confectionary products, so increasing shelf-life of products.
\end{abstract}

Keywords: polyphenols, grape seed, Vitis vinifera L., GC-MS analysis, antioxidant.

\section{Introduction}

Many confectionary products are food ones with essential storage terms. This fact determines a necessity of using fats with an essential stability to oxidation in their recipe compositions. Just oxidative rancidity is one of main processes, limiting storage terms of many food products [1]

Ways of increasing the oxidative stability of confectionary products may be characterized by three directions: the use of optimal ingredients, optimal processing methods and effective package [2]. An important role of using optimal ingredients is played by development of new technologies of products by using natural supplements as ingredients. They are sources of antioxidants that, on the one hand, are able to block the effect of free radicals and to defend a human from them, and from the other one, to act as an inhibitor of fats oxidation in the food matrix of a product.

Secondary products of grape processing and winemaking gain more and more popularity as antioxidants in fat-containing systems and are more and more in demand in food industry [3] 
It is conditioned by the presence of an essential amount of polyphenols with essential antioxidant properties in their composition. Introduction of such products in the composition of fat-containing products, for example, confectionary glaze, will favor decelerating oxidation processes of fats and prolonging storage terms of glaze and glazed products. This is a promising direction of improving their production. At the same time it is known, that powders of grape seeds may be used as an alternative of import cacao powders. But the technological process of creation of any products needs determining the composition of included raw materials, moreover taking into account the variety diversity of grape and an influence of the geographical factor on its quality.

Taking into account the aforesaid, the urgent problem of this study is to investigate the chemical composition of grape seed powders as natural sources of antioxidants of the phenol nature. Introduction of powders as an ingredient of confectionary products inhibits oxidation and hydrolysis of these products, in such a way increasing shelf-life of products.

\section{Materials and Methods}

Two types of white and red grape seed powders (Vitis vinifera L.) of the mixture of varieties Cabernet Sauvignon, Cabernet, Muscat Blanc à Petits Grains and Muscat (in approximately equal proportions) of the harvest of 2015-2017 years were used for the study. These grape varieties are widely cultivated in the Odessa region (Ukraine) and are a raw material for vine-making enterprises.

Powders were obtained under industrial conditions. At first grape seeds were separated from pomace, dried at a room temperature and subjected to the thorough purification (separation). Then GSP (grape seed powder) was obtained by superfine grinded. Another powder type DGSF (defatted grape seed flour) was obtained by extraction of oil of grape seeds by cold pressing. Pomace, created after grape seed pressing was superfine grinded up to flour. This powder type is a commercial product at the Ukrainian trade market, realized as a trademark OleoVita (Orion, Ukraine) (Fig. 1).

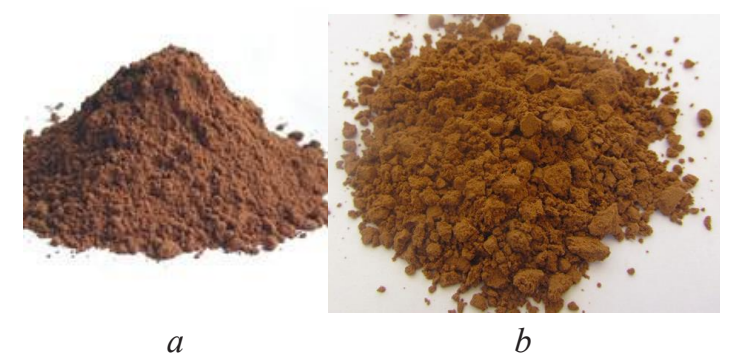

Fig. 1. Grape seeds powder: $a-\mathrm{GSP} ; b-\mathrm{DGSF}$

The chemical composition of powder extracts was studied by CG-MS analysis on the gas chromatograph Finnigan Focus GC (Thermo Fisher Scientific, USA) with the mass-selective detector (Thermo Electron Corporation, USA). The quartz capillary column HP-5MS with diameter $0,25 \mathrm{~mm}$ and length $30 \mathrm{~m}$, thickness of a film phase $-0,25 \mu \mathrm{m}$ was used in the experiment. Helium was used as a gas-agent. Identification of compounds by the retention time of peaks was conducted using the database of NIST05 Library. Mass spectrum of individual unknown compound was compared with the known compounds stored in the software database Library.

\section{Experimental procedures}

For conducting the study, there were prepared powder extracts by the maceration method. The batch of a sample with mass $5 \mathrm{~g}$ was placed in a conic flask and added with a correspondent solvent with volume $50 \mathrm{ml}$. The mixture was kept during 24 hours in a dark place, then filtered through a paper filter.

For studying a fat fraction of the powders, there was used ethyl alcohol (96\%, Dubliany alcohol plant, Ukraine) as a reagent.

Water-alcohol solutions were used as solvents for extracting phenolic compounds [4]. The composition of the solvents was determined, based on the realized studies on optimization of the maximal output of substances, extracted from the powder matrix. For these aims, there were real- 
ized preliminary CG-MS analysis, where mixtures with the content of isopropyl alcohol (Ineos Solvents, Germany) 20-100\% (w/w) were used. The comparative analysis of chromatogram demonstrated that the most output of phenol compounds is achieved at extraction of $50 \%$ of isopropanol $(w / w)$. The data for this amount of alcohol in mixed solution are given in the further discussion.

\section{Results}

Fig. 2, 3 present GC-MS chromatograms of water-ethanol extracts of both samples in the area of little retention times, corresponding to the content of volatile components, forming the fat phase of the powders.

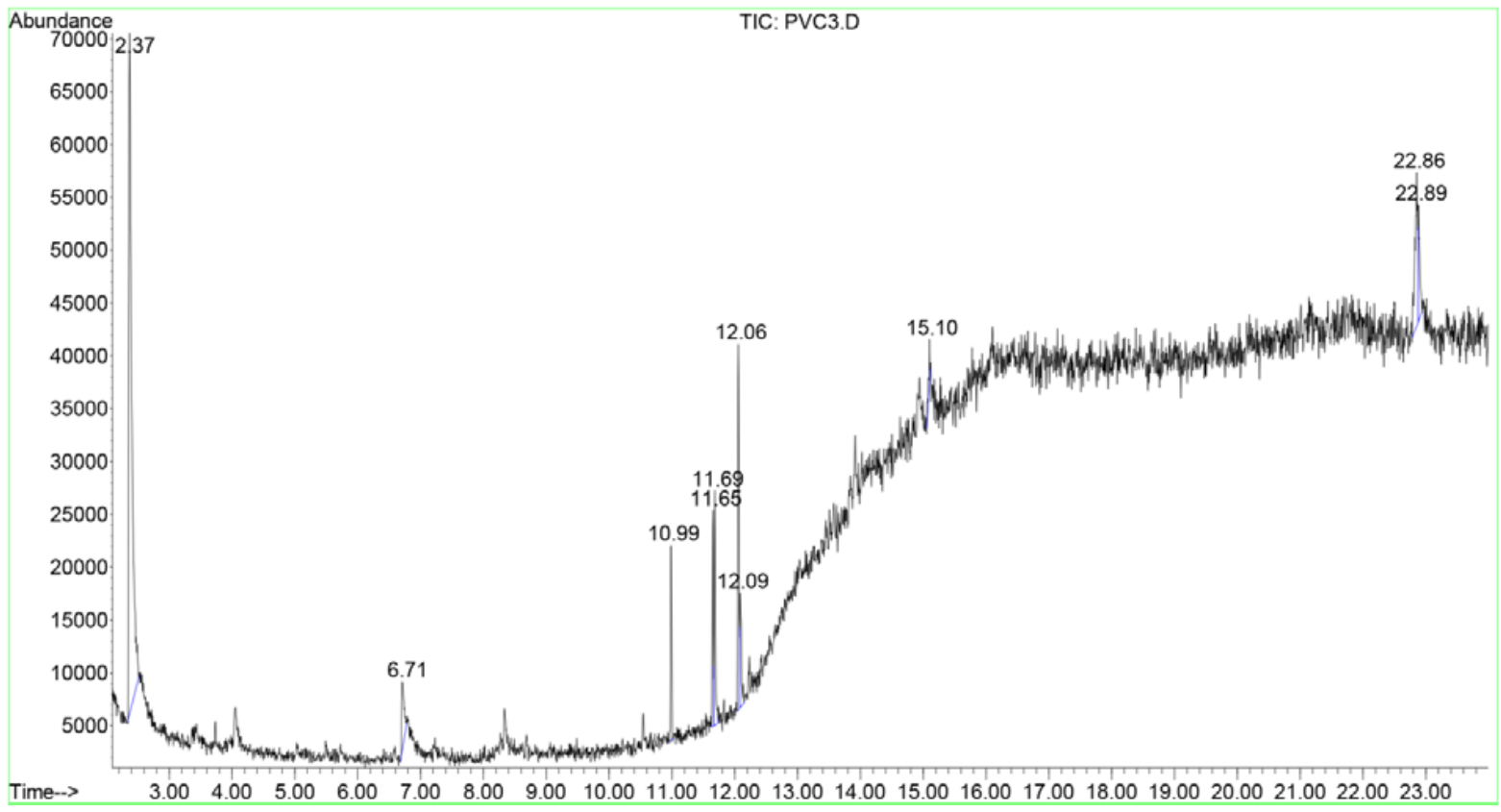

Fig. 2. GC-MS chromatogram of ethanol extract of the grape seed powder

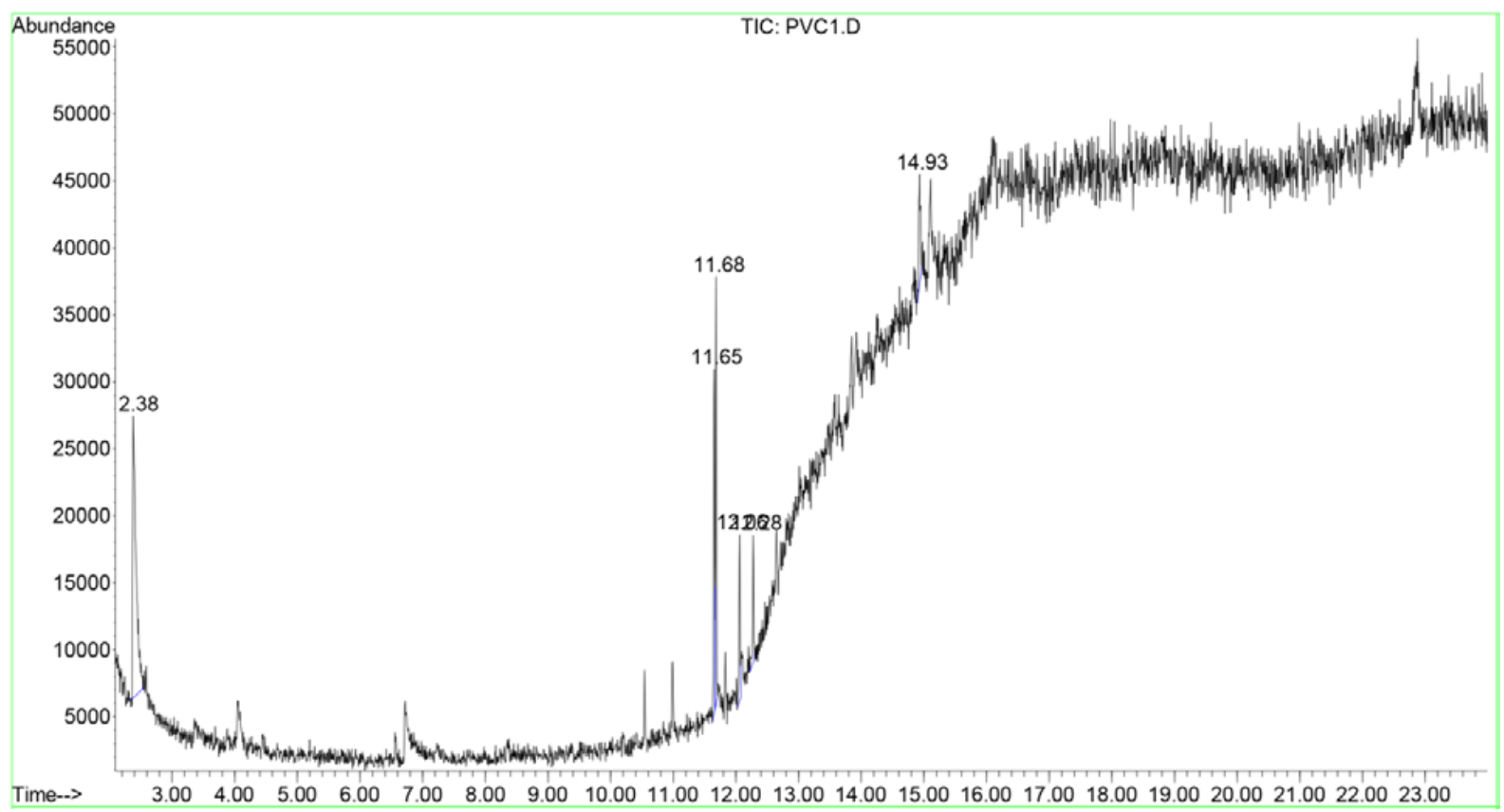

Fig. 3. GC-MS chromatogram of ethanol extract of the defatted grape seed flour 
On comparison of the mass spectra of the constituents with the NIST05 Library the compounds were characterized and identified (Table 1). As it can be seen on Table 1, the difference between the chemical compositions of the powders is observed at the expanse of linoleic and palmitic acids and partially at the expanse of the content of oleic and stearic acid.

Table 1

Identified in the ethanol extracts of samples by GC-MS analysis

\begin{tabular}{ccccc}
\hline Peak & $\begin{array}{c}\text { Retention } \\
\text { time, } \text { min }\end{array}$ & Name of the compound & GSP & DGSF \\
\hline 1 & 2,38 & gliceryn & + & + \\
2 & 6,71 & xanthosine & + & - \\
3 & 10,99 & palmitic acid, ethyl ester & + & + \\
4 & 11,65 & 9,12 -octadecadienoic acid, methyl ester & + & + \\
5 & 11,69 & oleic acid, methyl ester & + & - \\
6 & 12,06 & linoleic acid, ethyl ester & + & - \\
7 & 12,09 & ethyl oleate & & +
\end{tabular}

Table 2

Identified in the isopropanol extracts of samples by GC-MS analysis

\begin{tabular}{|c|c|c|c|c|}
\hline \multirow{2}{*}{ Peak } & \multirow{2}{*}{ Name of the compound } & \multirow{2}{*}{ Retention time, min } & \multicolumn{2}{|c|}{ Quantitative ratio, \% } \\
\hline & & & GSP & DGSF \\
\hline 1 & Hexanal & 9,58 & 0,3 & 0,1 \\
\hline 2 & Benzoic aldehyde & 10,26 & 2,0 & 3,3 \\
\hline 3 & Phenyl ethyl alcohol & 11,39 & 1,0 & 1,3 \\
\hline 4 & d-Mannose & 13,00 & 1,0 & 1,6 \\
\hline 5 & Purple aldehyde & 13,46 & 2,0 & 6,7 \\
\hline 6 & Camphene & 13,89 & 0,4 & 0,9 \\
\hline 7 & Cinnamon aldehyde & 14,01 & 3,0 & 4,0 \\
\hline 8 & Carvacrol & 14,59 & 2,0 & 4,0 \\
\hline 9 & E-citral & 14,92 & 1,0 & 1,5 \\
\hline 10 & Nerol & 15,56 & 4,0 & 5,2 \\
\hline 11 & Geraniol & 16,06 & 7,0 & 5,3 \\
\hline 12 & Borneol & 18,24 & 0,9 & 1,0 \\
\hline 13 & Linalool & 18,32 & 2,0 & 1,3 \\
\hline 14 & Gallic acid & 18,69 & 4,2 & 6,2 \\
\hline 15 & Octadecanoic acid & 19,60 & 3,9 & 3,0 \\
\hline 16 & Linoleic acid & 18,09 & 4,2 & 2,2 \\
\hline 17 & Hexadecanoic acid & 18,24 & 5,1 & 2,1 \\
\hline 18 & (9Z)-Octadecenoic acid & 19,62 & 5,0 & 2,0 \\
\hline 19 & Resveratrol & 19,21 & 3,2 & 1,2 \\
\hline 20 & Linolinic acid & 16,74 & 0,2 & 0,1 \\
\hline 21 & Elagic acid & 18,81 & 3,2 & 4,2 \\
\hline 22 & $\alpha$-caryophyllen & 21,01 & 1,0 & 1,0 \\
\hline 23 & Quercetin & 23,07 & 6,7 & 7,0 \\
\hline 24 & Quencetin-3-monoglucoside & 23,15 & 8,0 & 9,0 \\
\hline 25 & Quercetin-3-monoglucuronoside & 23,49 & 4,0 & 5,1 \\
\hline 26 & $\alpha$-terpeniol & 23,94 & 1,0 & 1,0 \\
\hline 27 & Catechine & 24,16 & 2,8 & 4,0 \\
\hline 28 & Epicatechine & 24,46 & 2,9 & 3,5 \\
\hline 29 & Camperferol & 24,49 & 7,1 & 7,9 \\
\hline 30 & Mericitin & 24,84 & 5,8 & 6,0 \\
\hline 31 & Lupeol & 27,41 & 1,0 & 0,8 \\
\hline 32 & Betulin & 27,54 & 2,1 & 2,2 \\
\hline
\end{tabular}

Note: *-phenolic compounds are marked by the black type 
Table 2 presents the results of studying GSP and DGSF extracts in isopropyl alcohol. On comparison of the mass spectra of the constituents with the NIST05 Library the thirty two compounds were characterized and identified. During the experimental research there were explored of GSP and DGSF extracts in isopropyl alcohol for powders of the grape harvest of 2015-2017 and different series of powders within one year. Despite the fact that the mixture of seeds of different varieties of grape was used in the study, the difference in the content of identified same substances in identical powders doesn't exceed 3,0-5,0 \%. These data testify to the fact that the ratio between different varieties in the mixture is observed in OleoVita powders, and also to the relative stability of the polyphenol composition of grape powders of different years of production.

Alongside with fatty acids, there were identified alcohols of the terpenes: carvacrol, nerol, geraniol, borneol, linalool, $\alpha$-terpeniol; monoterpenic aldehyde citral; terpenic carbohydrate $\alpha$-caryophyllen.

There was observed a series of aldehydes, such as benzoic, typical for vegetable seeds, and purple that is a product of oxidizing degradation of lignin.

Phenolic and polyphenolic compounds, presented by three classes: phenol acids, flavonoids and stilben, are marked by the black type in Table 2. Phenolic acids are presented as gallic and egallic acids, typical components of seeds of practically all grape varieties. The numerous class of flavonoids is presented by flavanols - catechine, epicatechine and flavonols - camperferol, mericitin, quercetin and its derivatives. Stilbens are presented by resveratrol.

\section{Discussion}

According to the data of the GC-MS chromatograms of ethanol extracts of the defatted grape seed powder takes place mainly as a result of a decreasing concentration of methyl and ethyl esters of unsaturated linoleic ( $\omega-6)$ and oleic ( $\omega-9)$ acids and saturated ones - palmitic and stearic (Table 1). According to the data of Table 1, the most extraction at pressing is achieved for linoleic and palmitic acids. Whereas the residual content of fats in the defatted grape seed powder at the level of $6-9 \%$ is achieved by the content of oleic and stearic acids.

The obtained data are in good agreement with the previous literature on chromatographic studies of the chemical composition of grape seeds, for example $[5,6]$.

As it is seen on Table 2, the presence of fatty acids is observed in extracts. The tendency to a decrease of the fatty acids content after cold pressing determines redistribution of the ratio between the content of components in GSP and DGSF extracts. Thus, the percent contribution of other compounds increases in DGSF.

The detected phenolic compounds in the isopropyl extract of GSP and DGSF samples are typical for powders of grape seeds of different varieties in other solvents, but in other quantity ratios that is proved by literary sources [7-18]. These phenolic compounds are antioxidants [18]. It gives reasons for using grape seed powders as a source of natural antioxidant in food technologies, in first turn - in production of fat-containing confectionary products. This problem is a subject of further experimental studies.

\section{Conclusions}

The study of ethanol extracts of GSP and DGSF samples allowed to establish the difference in the content of the fat phase of grape powders. These data are necessary for estimating a food value of products that powders may be used as a recipe component in.

The conducted chromatographic studies of the chemical composition of two types of grape seed powders as water-isopropanol extracts allowed to establish the presence of polyphenol compounds that, according to the literary data, have essential antioxidant properties in samples. Among the observed compounds there were identified phenol acids as gallic and egallic, flavanoids - catechine, epicatechine, camperferol, mericitin, quercetin and its derivatives, and also stilbens, presented by resveratrol. The obtained results testify to the good prospects of using powders, especially DGSF sample, as a source of natural antioxidants in confectionary products. This application allows to solve at least three problems: processing of wastes of vine-making industry, increase of shelf-life and the nutritional value of confectionary products. 


\section{References}

[1] Shahidi, F. (Ed.) (2015). Handbook of Antioxidants for Food Preservation. Elsevier, 514. doi: https://doi.org/10.1016/c2013-0-16454-9

[2] Talbot, G. (2010). Oxidation of confectionery products and biscuits. Oxidation in Foods and Beverages and Antioxidant Applications, 344-368. doi: https://doi.org/10.1533/9780857090331.2.344

[3] García-Lomillo, J., González-SanJosé, M. L. (2016). Applications of Wine Pomace in the Food Industry: Approaches and Functions. Comprehensive Reviews in Food Science and Food Safety, 16 (1), 3-22. doi: https://doi.org/10.1111/1541-4337.12238

[4] Aires, A. (2017). Phenolics in Foods: Extraction, Analysis and Measurements. Phenolic Compounds, 61-88. doi: https://doi.org/10.5772/66889

[5] Orsavova, J., Misurcova, L., Ambrozova, J., Vicha, R., Mlcek, J. (2015). Fatty Acids Composition of Vegetable Oils and Its Contribution to Dietary Energy Intake and Dependence of Cardiovascular Mortality on Dietary Intake of Fatty Acids. International Journal of Molecular Sciences, 16 (12), 12871-12890. doi: https://doi.org/10.3390/ijms160612871

[6] Sousa, J., Pedroso, N., Borges, L., A., G., Paula, J., Conceicao, E. (2014). Optimization of Ultrasound-assisted extraction of polyphenols, tannins and epigallocatechin gallate from barks of Stryphnodendron adstringens (Mart.) Coville bark extracts. Pharmacognosy Magazine, 10 (38), 318. doi: https:// doi.org/10.4103/0973-1296.133287

[7] Lafka, T.-I., Sinanoglou, V., Lazos, E. S. (2007). On the extraction and antioxidant activity of phenolic compounds from winery wastes. Food Chemistry, 104 (3), 1206-1214. doi: https://doi.org/10.1016/j. foodchem.2007.01.068

[8] Shi, J., Yu, J., Pohorly, J. E., Kakuda, Y. (2003). Polyphenolics in Grape Seeds-Biochemistry and Functionality. Journal of Medicinal Food, 6 (4), 291-299. doi: https://doi.org/10.1089/109662003772519831

[9] Kamel, B. S., Dawson, H., Kakuda, Y. (1985). Characteristics and composition of melon and grape seed oils and cakes. Journal of the American Oil Chemists' Society, 62 (5), 881-883. doi: https:// doi.org/10.1007/bf02541750

[10] Ananga, A., Obuya, J., Ochieng, J., Tsolova, V. (2017). Grape Seed Nutraceuticals for Disease Prevention: Current Status and Future Prospects. Phenolic Compounds - Biological Activity, 119-137. doi: https://doi.org/10.5772/66894

[11] Li, H., Wang, X., Li, P., Li, Y., Wang, H. (2008). Comparative Study of Antioxidant Activity of Grape (Vitis vinifera) Seed Powder Assessed by Different Methods. Journal of Food and Drug Analysis, $16(6), 67-73$.

[12] Reddy, G. V. B., Sen, A. R., Nair, P. N., Reddy, K. S., Reddy, K. K., Kondaiah, N. (2013). Effects of grape seed extract on the oxidative and microbial stability of restructured mutton slices. Meat Science, 95 (2), 288-294. doi: https://doi.org/10.1016/j.meatsci.2013.04.016

[13] Casazza, A. A., Aliakbarian, B., Mantegna, S., Cravotto, G., Perego, P. (2010). Extraction of phenolics from Vitis vinifera wastes using non-conventional techniques. Journal of Food Engineering, 100 (1), 50-55. doi: https://doi.org/10.1016/j.jfoodeng.2010.03.026

[14] Kurt, S. (2016). The Effects of Grape Seed Flour on the Quality of Turkish Dry Fermented Sausage (Sucuk) during Ripening and Refrigerated Storage. Korean Journal for Food Science of Animal Resources, 36 (3), 300-308. doi: https://doi.org/10.5851/kosfa.2016.36.3.300

[15] Kulkarni, S., DeSantos, F. A., Kattamuri, S., Rossi, S. J., Brewer, M. S. (2011). Effect of grape seed extract on oxidative, color and sensory stability of a pre-cooked, frozen, re-heated beef sausage model system. Meat Science, 88 (1), 139-144. doi: https://doi.org/10.1016/j.meatsci.2010.12.014

[16] Rockenbach, I. I., Rodrigues, E., Gonzaga, L. V., Caliari, V., Genovese, M. I., Gonçalves, A. E. de S. S., Fett, R. (2011). Phenolic compounds content and antioxidant activity in pomace from selected red grapes (Vitis vinifera L. and Vitis labrusca L.) widely produced in Brazil. Food Chemistry, 127 (1), 174-179. doi: https://doi.org/10.1016/j.foodchem.2010.12.137

[17] Saykova, I., Tylkowski, B., Popovici, C., Peev, G. (2018). Extraction of phenolic and flavonoid compounds from solid wastes of grape seed oil production by cold pressing. Journal of Chemical Technology and Metallurgy, 53 (2), 177-190.

[18] Ma, Z., Zhang, H. (2017). Phytochemical Constituents, Health Benefits, and Industrial Applications of Grape Seeds: A Mini-Review. Antioxidants, 6 (3), 71. doi: https://doi.org/10.3390/antiox6030071 